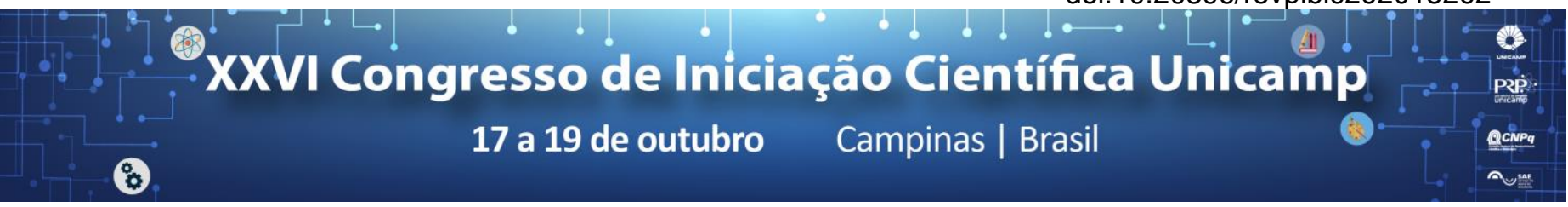

\title{
Estudo das Equações do Cálculo do Coeficiente de Dispersão usando Análise Correlacional
}

\author{
Camila P. Melchior*, Michele S. Lopes, Eva C. M. Oliveira, Júlia K. Ambrosio, Bruno M. Brentan, Laura M. C. F. \\ Fais, Lubienska C. L. J. Ribeiro.
}

\begin{abstract}
Resumo
Uma variável importante para analisar e parametrizar modelos de qualidade da água é o coeficiente de dispersão longitudinal, que analisa a dispersão do poluente no rio, e que não é um parâmetro normativo de avaliação, pois não há um padrão de cálculo. Diversas são as fórmulas para quantifica-lo, este projeto analisou 14, elas consideram as características físicas do rio que interferem no coeficiente. A análise correlacional, com mapas auto-organizáveis e análise de componentes principais, buscou relações entre as variáveis e analisou a aplicabilidade das equações buscando contribuir com trabalhos futuros e a padronização do coeficiente.
\end{abstract}

\section{Palavras-chave:}

mapas auto-organizáveis, dispersão longitudinal, escomento em canais

\section{Introdução}

O coeficiente de dispersão longitudinal $\left(E_{L}\right)$ é um parâmetro físico que pode contribuir no monitoramento da poluição e degradação de recursos hídricos, ele representa a advecção-dispersão de poluentes em um curso d'água. Existem diversas formas de calculá-lo, este estudo foca naquelas que com ensaios práticos relacionam características físicas do canal com o coeficiente. Há uma dificuldade em aplicá-lo, pois de cada equação saem valores bem diferentes, por isso a análise correlacional, que encontra relações entre variáveis, se mostra importante, para avaliar as relações sugeridas. Foi usada a rede neural SOM (Self-organizing maps), mapas autoorganizáveis, estas redes processam informações baseadas nos neurônios humanos, e a análise de componentes principais, PCA (principal component analysis), que apresenta uma combinação linear das relações. Este projeto busca, com a compilação de 14 equações, realizar estas análises para encontrar relações, identificando quais variáveis interferem mais no coeficiente e quais equações consideram tais relações. Para isso foram coletadas características físicas de um canal natural e um artificial.

\section{Resultados e Discussão}

Foram usados dados do trabalho empírico de Oliveira (2017), realizado na Faculdade de Tecnologia em um canal artificial, e foi feito novo trabalho empírico em um trecho do Ribeirão Pinhal, em Limeira. Foram simulados um despejo de poluente, cloreto de sódio, para observar a dispersão, sendo as coletas baseadas na metodologia de Lopes (2016), que capta as variações das concentrações nas três dimensões do canal. Além de medidas as 8 variáveis hidráulicas necessárias para 0 cálculo do coeficiente, de acordo com as equações. Por fim foram montados os bancos de dados das análises, eles contêm as variáveis e as concentrações de cada ponto analisado. $O$ coeficiente $E_{L}$ deve representar a capacidade da água em dispersar um poluente, ou seja, fazer variar sua concentração ao longo do canal e do tempo, assim se considera que as variáveis relacionadas à concentração também se relacionam com o coeficiente. As relações aparecem com a leitura dos mapas, esta é feita através das semelhanças topológicas entre os mapas de cada variável, cores e padrões semelhantes indicam relações positivas, cores e padrões opostos indicam relações negativas. Além da leitura dos gráficos da PCA, esta é baseada nos vetores das variáveis, vetores mais próximos representam relação positiva entre as varáveis, vetores distantes indicam relações negativas.

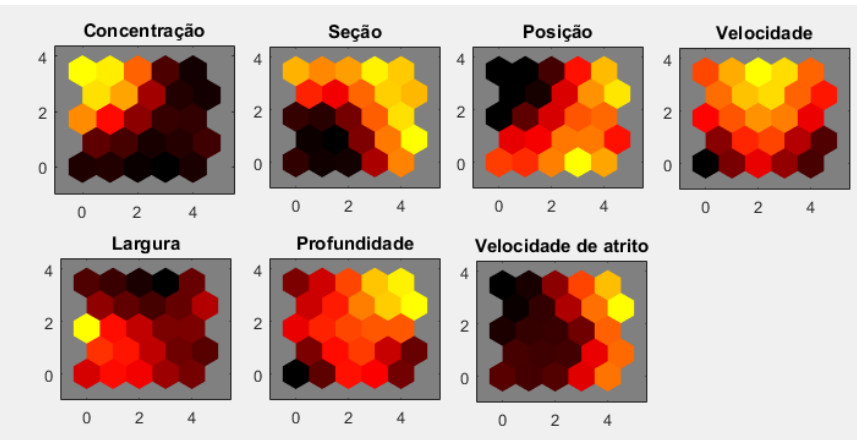

Figura 1. SOM para equação de Fischer (1975) aplicada no canal natural

\section{Conclusões}

Das variáveis que foi possível definir relações: profundidade, velocidade de atrito e raio hidráulico têm relação negativa com a concentração; velocidade média e largura do canal apresentaram, na maioria dos casos, relação positiva, porém ambas relações menos nítidas que as anteriores. As equações que usam as relações de acordo com as análises são as de Devens (2010), Fischer (1975), Nikora \& Sukhodolov (1993) e Vargas \& Mellado (1994). As análises ainda podem ser aprimoradas, principalmente quanto a variáveis que não puderam ter suas relações definidas por este estudo.

\section{Agradecimentos}

PIBIC, minha orientadora Lubienska, Michele, e todos alunos e funcionários envolvidos no trabalho de campo e em laboratório.

LOPES, M. S. Montagem de um canal retangular hidráulico para estudo de dispersão de um traçador conservativo. 2016. 157 f. Dissertação (Mestrado em Tecnologia) - Faculdade de Tecnologia, Universidade Estadual de Campinas, Limeira-SP.

OLIVEIRA, E. C. M. Determinação do Coeficiente de Dispersão de um canal para validação de um software de fluidodinâmica computacional (CFD). 2017 60 f. Dissertação (Mestrado em Tecnologia) - Faculdade de Tecnologia, Universidade Estadual de Campinas, Limeira-SP. 